\title{
V Congresso Paulista de Medicina do Esporte V Jornada Internacional de Medicina do Esporte III Simpósio Dante Pazzanese de Cardiologia do Esporte e II Simpósio de Traumatologia do Esporte
}

\author{
9, 10 e 11 de maio de 2002 - São Paulo, SP \\ RESUMOS
}

\author{
PERFIL DE IDOSOS ATIVOS E ASILADOS: ANÁLISE \\ DE FORÇA E RESISTÊNCIA AERÓBIA \\ Autor: Adriana B. Truccolo \\ Co-autores: Gonçalves A.K., Almeida D., Pinto C.G. \\ Apresentador: Adriana Truccolo \\ Serviço: Universidade Luterana do Brasil
}

Introdução: $\mathrm{O}$ envelhecimento relacionado a fase da terceira idade tem sido mais estudado nos últimos anos, propiciando mais conhecimento sobre este processo que cada vez mais pessoas vivenciam. Uma das idéias comuns é que com o passar das décadas algumas variáveis neuromotoras básicas diminuem, baseado principalmente na queda de atividade. Entre estas variáveis a força e a resistência aeróbica são algumas das quais mais se evidenciam porque afetam diretamente a realização de atividades diárias, causando com sua diminuição a execução de tarefas simples como levantar-se de uma cadeira e deslocar-se até um ponto para apanhar um objeto. A capacidade para praticar exercícios é afetada diretamente devido a esta diminuição das capacidades motoras básicas, criando um círculo vicioso. Entre 30 a 80 anos a força muscular diminui de 30 a $40 \%$ nos homens e em menor grau nas mulheres. A capacidade aeróbica máxima também diminui, porém pessoas idosas ativas têm capacidade aeróbica maior do que as da mesma idade e mesmo mais jovens. Este último aspecto comprova que pessoas idosas quando ativas podem manter um nível satisfatório de força, resistência, agilidade, equilíbrio, entre outras capacidades. Uma outra questão presente nos estudos do envelhecimento humano é a influência da institucionalização no processo de envelhecimento, ou seja, como o idoso asilado comporta-se em relação ao idoso não-asilado. Material/casuística e métodos, ou caso clínico: A partir destas premissas realiza-se esta investigação com dois grupos de pessoas com idade superior aos 60 anos de ambos os sexos: o grupo A ativo $(\mathrm{n}=21)$ praticante de atividades físicas duas vezes por semana e o grupo $B(n=21)$ não praticante e residindo em asilo. A idade varia entre 61 e 83 anos de idade com aproximadamente $50 \%$ de homens e mulheres no grupo A e $70 \%$ de mulheres no grupo B. Os instrumentos para avaliar as variáveis força (membros inferiores e membros superiores) e resistência aeróbica são do 'Senior Fitness Test Manual' propostos por Rikli e Jones. Resultados/conclusão: Os resultados evidenciam que há uma diferença significativa ao nível de 5\% entre os dois grupos nos três testes aplicados (um teste para força de membros superiores, um teste para força de membros superiores e um teste para resistência aeróbica) e nas duas variáveis analisadas. No grupo B $20 \%$ dos idosos não conseguem realizar os testes de força e $23 \%$ o teste de resistência aeróbica. Quanto a resistência aeróbica, no grupo A $90 \%$ atingem resultados abaixo do normal para sexo e faixa etária, enquanto no grupo B todos resultados são abaixo do normal para sexo e idade. A força de membros inferiores de $80 \%$ do grupo A apresenta resultados abaixo do limite esperado para sexo e faixa etária e $20 \%$ dentro dos resultados esperados, já no grupo B $100 \%$ apresentam resultados abaixo do limite esperado. Na força de membros superiores, mais pessoas atingem resultados dentro do limite esperado para sexo e idade em ambos os grupos. No grupo A apenas $23 \%$ ficam abaixo do limite esperado, enquanto $61 \%$ estão dentro do limite e $14 \%$ acima do limite esperado. Já no grupo B, a metade obtém resultados abaixo do limite e a outra metade consegue resultados dentro do limite esperado. Estes dados comprovam a diferença entre idosos asilados e não-asilados, demonstrando uma diferença marcante e evidenciando que os asilos necessitam de um programa de atividades para propiciar uma vida melhor. Porém, também evidenciam que mesmo num grupo de idosos ativos as capacidades motoras ainda não são suficiente estimuladas, alertando para o fato de que a realidade do envelhecimento é marcada pela queda do nível de atividade, dificultando a independência funcional necessária. Com este trabalho evidencia-se a necessidade de um programa de atividades físicas para terceira idade que atinja estas variáveis básicas e que possibilite um envelhecimento funcional para todas as pessoas idosas, independente de seu modo de vida (institucionalizado ou não).

AVALIAÇÃO DO DESEMPENHO MOTOR E APTIDÃO FÍSICA EM ESCOLARES DE 14 A 17 ANOS DE UMA INSTITUIÇÃO PARTICULAR COLÉGIO NOSSA SENHORA CONSOLATA

Autor: Gisele Giufrida

Co-autores: Giufrida G., Delphino L.C.A., Kiss M.AP.D.M., Barros R.

Apresentador: Gisele Giufrida

Serviço: CENESP - USP Ladesp

O objetivo deste estudo foi avaliar os níveis de aptidão física e desempenho motor em escolares de ambos os sexos conforme diferentes grupos. Para tanto foram avaliados 256 alunos, sendo 121 do sexo masculino $(63 \mathrm{~kg} \pm 13 ; 169 \mathrm{~cm} \pm 8)$ e 135 do sexo feminino $(54 \mathrm{~kg} \pm$ $8 ; 160 \mathrm{~cm} \pm 6)$. Testes motores realizados: corrida de 12 minutos, resistência abdominal em 30seg., flexão de braço em 30seg. e impulsão vertical: salto vertical. Os resultados indicam uma diferença significativa entre os grupos para as variáveis abdominal, 12 minutos, salto vertical, peso altura e flexão de braço: a idade não mostrou correlação significativa com desempenho, conclui-se que o desempenho motor dos alunos adolescentes desta instituição de ensino não está relacionado com a idade e embora tenha havido diferença significativa entre os sexos e entre os grupos etários. 


\section{"GANGLION" DE LIGAMENTO CRUZADO ANTE- RIOR - RELATO DE CASO}

Autor: André Pedrinelli

Co-autores: Castellana F.B., Fontes R.B.V., Coelho R.F., Silva L.A.M.

Apresentador: André Pedrinelli

Serviço: IOT-FMUSP

Introdução: Um ganglion é uma formação cística próxima a articulações ou bainhas tendinosas, freqüentemente encontrado no punho, pé e joelho. Ganglia intra-articular do joelho são raros, e a maioria destes estão localizados no ligamento cruzado anterior (LCA). O quadro clínico destes ganglia é composto por dor e limitação de movimento do joelho, causando importante prejuízo ao paciente. Os sintomas são inespecíficos, e ganglia são geralmente diagnosticados por ressonância magnética (RM) ou artroscopia. Nem todos os ganglia diagnosticados por RM precisam ser submetidos à cirurgia, mas apenas aqueles com sinais e sintomas clínicos. Relato de caso: Um homem de 29 anos apresentou dor no joelho esquerdo durante uma corrida de maratona. $\mathrm{O}$ exame físico revelou limitação da extensão máxima do joelho e dor na face posterior do joelho esquerdo. Radiografias do joelho esquerdo foram normais, mas a RM revelou uma estrutura cística multilobulada adjacente ao LCA, que lembrava um ganglion. A massa foi removida por artroscopia, e o exame patológico revelou um cisto sinovial. A recuperação do paciente foi excelente, e ele retomou sua rotina de treinamento normal cinco meses depois.

\section{ATLETAS VETERANOS (AV): EXERCÍCIO FÍSICO VIGOROSO (EFV) E PREVENÇÃO DE DOENÇAS CARDIOVASCULARES (DCV): QUANTO MAIS IN- TENSO MELHOR?}

Autor: Cláudio Baptista

Co-autores: Ghorayeb N., Dioguardi G., Smith P., Mauzel S.M., Batlouni M.

Apresentador: Cláudio Baptista

Serviço: Centro Olímpico Treinamento e Pesquisa e Cardioesporte Instituto Dante Pazzanese de Cardiologia

Objetivo: Exercício Físico regular é preventivo para as DCV, agindo nos fatores de risco. Sua intensidade ainda é polêmica quando comparamos EFV com Exercícios Leves a Moderados (EFLM), em relação a qual oferece maiores benefícios. Material e métodos: 16 $\mathrm{AV}$, idade 50 a 73 anos, 12 femininos, modalidade natação (GN), tempo médio e contínuo de 10 anos de treinamento semanal (TS) de alta intensidade -4.000 a $20.000 \mathrm{~m}$ e duração de $4 \mathrm{~h}$ a $7 \mathrm{~h}$, sendo 10 portadores de hipertensão arterial (HA), e 40 no grupo caminhadas (GC), pareados quanto à idade, tempo de caminhadas 10 anos e TS de 5 a $7 \mathrm{~h}$ e total de 35 a $40 \mathrm{~km}$ e sem DCV. Ambos grupos submetidos à avaliação cardiológica e exames complementares de rotina. Resultados: Variáveis Fisiológicas (VF): GN - VO2 max. 25,06 a $61,1 \mathrm{LO} 2 / \mathrm{kg} / \mathrm{min}$, tempo total esteira (TTE) 8', 30 a 12'; GC VO2max. 24,5 a 38,6LO2/kg/min. e TTE 7', !0a 10'; Perfil Lipídico: GN em $\mathrm{mg} / \mathrm{dl} \mathrm{CT}<240 \mathrm{em} 13$ (81\%), HDL-C > 45 em 16 (100\%), LDL-C < 160 em 12 (75\%), TG < 200 em 16 (100\%) e índice de massa corpórea $(\mathrm{IMC})<25 \mathrm{em} 16(100 \%$.). GC CT < $240 \mathrm{em} 25(62,5 \%)$, HDLC > 45 em $25(62,5 \%)$, LDL-C < 160 em 28(70\%), TG < 200 em 26 $(65 \%)$ e IMC $<25$ em 20 (50\%). GN 10 com HA somente $1 \mathrm{AV}$ com espessura de septo e parede de ventrículo esquerdo $12 \mathrm{~mm}$. GN em 4
AV foram detectadas anormalidades cardiovasculares e foram reorientados quanto à intensidade na natação. Os autores comentam os resultados. Conclusão: os resultados sugerem que o EFV habitual traz maiores benefícios em relação aos EFLM principalmente devido > HDL (37,5\%), < TG (35\%), < IMC (50\%) e > VF e não contribuindo para um aumento da HVE nos portadores de HA e anos de TS, superando os eventuais riscos, porém requerendo avaliação cardiológica com maior periodicidade.

\section{VERIFICAÇÃO DA RESPOSTA DE ACUIDADE VI- SUAL SEM CORREÇÃO E PRESSÃO INTRA-OCULAR COMPUTADORIZADA DE NÃO-CONTATO EM JOGA- DORES DE FUTEBOL AMADORES E PROFISSIONAIS}

Autor: Emidio Valente Tavares

Co-autores: Oliveira O.N., Mendes S.B., Rabbony Y.M., Apelbaun B.

Apresentador: Obidulio Naves de Oliveira

Serviço: Seção de Oftalmologia do Departamento Médico da Associação Portuguesa de Desportos

Introdução: A importância da visão dentro dos padrões normais de acuidade é fundamental em atletas que necessitam de reflexos rápidos, como é o caso de futebolistas que precisam em frações de segundos decidir uma jogada durante o transcorrer de uma partida. Objetivo: Verificar possíveis alterações de acuidade visual e pressão intra-ocular em futebolistas. Material e métodos: Foram avaliados 127 atletas futebolistas provenientes de cinco categorias: infantil (28), juvenil (24); Juniores (27), profissionais (24) e futebol feminino (24). A idade de todos os atletas variou de 14 a 33 anos. A verificação do grau de acuidade visual foi medido pela escala de Snellen, considerando a distância de $6 \mathrm{~m}$. A pressão intra-ocular de não contato foi medida utilizando-se um tonômetro computadorizado (TX-10, Canon, EUA). A auto-refração (refração objetiva) foi medida utilizando - se um auto - refrator computadorizado (R-30, Canon, EUA). Resultados: 56 atletas (44\%) apresentaram alterações de auto-refração, consideradas de grau mais ou menos importantes em um ou ambos os olhos. No teste de acuidade visual, $3 \%$ e $2,4 \%$ dos atletas apresentaram em olho direito (OD) e olho esquerdo (OE), somente 20/100 e 20/200 pés de visão, respectivamente. Em uma atleta do futebol feminino foi constatada catarata puntata congênita. Os resultados da tonometria mostraram, em cinco atletas de cor negra, quadro suspeito de glaucoma. Conclusão: O estudo comprovou a importância da oftalmologia como medida preventiva e/ou corretiva na identificação de possíveis alterações oftalmológicas em atletas futebolistas, devendo ser uma prática rotineira nesse esporte.

\section{SEGURANÇA DO TESTE DE UMA RESISTÊNCIA} MÁXIMA EM CORONARIOPATAS

Autor: Wladimir Musetti Medeiros

Co-autores: Rodrigues R.M., Scarparo C.D.B., Gun C., Araújo Jr. E.B.A., Luca F.A., Goes C.S.S.

Apresentador: Rafael Montenegro Rodrigues

Serviço: Hospital Geral de Grajaú - Universidade de Santo Amaro

Introdução: Programas de Reabilitação Cardíaca devem se basear numa tríade de capacidade aeróbia, flexibilidade e força. Para que o treinamento de força/resistência seja bem prescrito, em qualquer situação, é necessário que se determine a capacidade de carga máxi- 
ma, delimitada no teste de uma resistência máxima (1RM). Sua estimativa incorreta ocasiona prescrição inadequada da carga e rendimento subestimado no treinamento de força/resistência. Objetivos: Padronização do Teste de Uma Repetição Máxima (1RM) e determinar a sua segurança cardiovascular e sua viabilidade de aplicação em indivíduos coronariopatas. Casuística e métodos: Randomizados 16 pacientes com diagnóstico de Infarto Agudo do Miocárdio (IAM) e foram submetidos a extensão de joelho com carga inicial de $10 \mathrm{~kg}$, em expiração, acrescido de $5 \mathrm{~kg}$ e $1 \mathrm{~kg}$, com intervalo de 2 minutos, até execução incorreta do movimento e flexão de cotovelo com carga inicial de $5 \mathrm{~kg}$, em expiração, acrescido de $1 \mathrm{~kg}$, com intervalo de 2 minutos, até execução de apenas 4 movimentos para estimativa de $80 \%$ de 1RM. Foram avaliados os seguintes parâmetros: segmento ST (Holter ECAFIX), pressão arterial sistólica (PAS) e diastólica (PAD) - (Monitor ECAFIX), frequiência cardíaca (FC) (Polar Beat), Oximetria de Pulso (Oxifast TAKAOKA) e percepção subjetiva de esforço (ipeBORG) nos 7 momentos (A, B, C, D, E, F, G) descritos abaixo. (A) Repouso Inicial, (B) teste de 1RM, (C) 4 repetições com $80 \%$ de $1 \mathrm{RM}$, (D) 15 repetições com $50 \%$ de $1 \mathrm{RM}$ para extensão de joelho, (E) 4 repetições com $80 \%$ de 1RM, (F) isometria em flexão de $90^{\circ}$ de cotovelo com $80 \%$ de 1RM durante 40 segundos e (G) 2 minutos de repouso após a conclusão de todos os testes e comparados em relação aos parâmetros de repouso (momento A). Resultados: Pressão Arterial Sistólica - (B) 3,1\%; (C*) 8,0\%; (D*) 16\%; (E*) 30,3\%; (F*) 41\%; (G) -1,9\%. Pressão Arterial Diastólica - (B) -3,1\%; (C) -2,4\%; (D) 2,2\%; (E*) 32,9\%; (F*) 46,8\%; (G) -4,9\%. Frequiência Cardíaca - (B*) 11,7\%; (C*) 22,9\%; (D*) 25,6\%; (E*) 36,6\%; (F*) 44,0\%; (G) 3,7\%. Oximetria de Pulso sem variações ou alterações em nenhum dos 7 momentos. Segmento ST - sem variações ou alterações em nenhum dos 7 momentos. Análise estatística realizada através de Student-T apresentando $\mathrm{P}<0,05$ para PAS, PAD e FC nas situações assinaladas (*). Conclusão: Com base nos resultados acima expostos, pudemos concluir que o teste de $1 \mathrm{RM}$ mostrou-se seguro no aspecto cardiovascular para a amostra estudada. O Protocolo GECAF-HGG mostrou-se rápido e eficaz para mensuração da carga máxima dos indivíduos. Concluiu-se que a PAS, a PAD e a FC sofreram aumentos importantes em situações com cargas menores e maior número de repetições e durante a isometria e também que exercícios com membro superior apresentaram as alterações mais importantes em relação ao repouso do que exercícios para membros inferiores.

ALTERAÇÕES DA FREQÜÊNCIA CARDÍACA, PRESSÃO ARTERIAL, PERCEPÇÃO DO ESFORÇO E SEGMENTO ST DURANTE TESTE DE 1RM, TREINO DE FORÇA. RESISTÊNCIA LOCALIZADA E ISOMETRIA ENTRE CORONARIOPATAS TREINADOS E NÃO TREINADOS

Autor: Wladimir Musetti Medeiros

Co-autores: Rodrigues R.M., Scarparo C.D.B., Gun C., Araújo Jr. E.B., Luca F.A., Goes C.S.

Apresentador: Wladimir Musetti Medeiros

Serviço: GECAF - Hospital Geral do Grajaú - Universidade de Santo Amaro

Introdução: Os exercícios com resistência tanto visando o ganho de força como o de resistência muscular localizado estão cada vez mais presentes nos protocolos de reabilitação cardíaca, porem al- guns guidelines preconizam um período de trabalho aeróbio inicial antes do treinamento resistido. Objetivos: Verificar as diferenças de freqüência cardíaca, pressão arterial sistólica e diastólica, percepção de esforço e segmento ST durante o teste de 1 resistência máxima (1RM), treino de força, treino de resistência muscular localizada (RML) e isometria em pacientes pós infarto agudo do miocárdio (IAM) treinados e não treinados. Casuística e métodos: Grupo A, 8 pacientes IAM, sexo masculino, 53,2 anos, sedentários. Grupo B 8 pacientes IAM, sexo masculino, 56 anos, submetidos a exercícios aeróbios em bicicleta ergométrica durante 1 mês, 3 vezes por semana durante 30 minutos. Foram avaliados os seguintes parâmetros: segmento ST (Holter ECAFIX), pressão arterial sistólica (PAS) e diastólica (PAD) - (Monitor ECAFIX), freqüência cardíaca (FC) (Polar Beat), Oximetria de Pulso (Oxifast TAKAOKA) e percepção subjetiva de esforço (ipeBORG) nos 7 momentos (A, B, C, D, E, F, G) descritos abaixo. (A) Repouso Inicial, (B) teste de 1RM, (C) 4 repetições com $80 \%$ de $1 \mathrm{RM}$, (D) 15 repetições com 50\% de 1RM para extensão de joelho, (E) 4 repetições com 80\% de 1RM, (F) isometria em flexão de $90^{\circ}$ de cotovelo com $80 \%$ de 1 RM durante 40 segundos e (G) 2 minutos de repouso após a conclusão de todos os testes. Resultados: A analise do segmento ST não apresentou alteração significativa, a freqüência cardíaca, pressão arterial sistólica e diastólica do grupo treinado apresentaram medias superiores as medias do grupo de sedentários nas situações (B, C, D, G). O grupo treinado apresentou medias inferiores as medias do grupo sedentário nas situações $(\mathrm{E}, \mathrm{F})$. Os resultados não apresentaram nível de significância $(\mathrm{P}<0,05)$ através da analise estatística de t-Student. Conclusão: Os resultados demonstram que o teste de 1RM, treino de força, de resistência localizada são seguros tanto para pacientes sedentários como treinados. Exercícios de resistência muscular localizada apresentam maiores valores de FC, PAS, PAD em relação aos exercícios de força. As variações de FC, PAS, PAD durante exercícios com os membros superiores não são tão marcantes nos pacientes treinados quando comparados aos sedentários. Concluímos com os resultados obtidos com esta amostra que a ausência de uma fase inicial de treinamento aeróbio não é uma contra indicação para os exercícios resistidos.

\section{ALTERAÇÕES IMUNITÁRIAS RELACIONADAS AO EXERCÍCIO FÍSICO}

Autor: Alberto O. Gotfryd

Co-autor: Michelucci M.A.

Apresentador: Alberto O. Gotfryd

Serviço: Universidade de Mogi das Cruzes

Introdução: Esportes, em geral, podem ser considerados benéficos para a saúde física e mental. Além disso, sabe-se que o exercício regular moderado aumenta a resistência a doenças infecciosas comuns, em decorrência da elevação das taxas circulantes de linfócitos, células exterminadoras (NK), citocinas, polimorfonucleares e imunoglobulinas. Em contraste, treinamento excessivo ou "overtraining", em atletas de elite, está associado ao aumento da susceptibilidade a infecções. Isto se deve ao fato de, nestes, ocorrer, freqüentemente, alterações nas concentrações celulares de importantes componentes da resposta imunológica, como diminuição da oferta de combustíveis celulares, regulação para baixo dos neutrófilos levando a neutropenia e linfocitopenia. Além disso, são descritas mudanças no fluxo leucocitário, diminuição dos níveis de imunoglobu- 
linas, como a $\operatorname{IgA}$, além do estresse psicológico também conhecido imunossupressor. Metodologia: Foi realizada revisão bibliográfica através de sistema de busca em importantes bases de dados médicos (MEDLINE, BIREME, LILACS) utilizando-se os termos "Sistema Imunológico", "Exercício Físico", "Atividade Física" e "Atletas", entre os anos de 1993 e 2001. Conclusões: O exercício físico é indicado na prevenção e no tratamento adjuvante de um grande número de doenças. No entanto, sua prescrição e acompanhamento devem ser muito bem elaborados, a fim de se obter todos os benefícios que ele proporciona sem provocar eventuais riscos deletérios relacionados ao excesso.

\section{CONHECIMENTOS E ATITUDES MÉDIAS FRENTE AO DOPING}

Autor: Marco Michelucci

Apresentador: Marco Michelucci

Serviço: Sociedade Paulista de Medicina Desportiva e Escola Educação Física Esportes - USP

O objetivo deste trabalho foi verificar os conhecimentos, atitudes e opiniões médicas frente ao doping. Foram então entrevistados 168 profissionais da saúde sendo 98 homens e 70 mulheres das clínicas médicas $(44,64 \%)$, cirúrgico-ortopédicas $(23,21 \%)$, pediátricas $(22,02 \%)$ e odontológicas $(10,12 \%)$. Embora a maioria $(74,40 \%)$ tenha obtido informações sobre doping, apenas $28,10 \%$ as obteve em literatura médica. Talvez por isso que somente $2,98 \%$ dos profissionais entrevistados afirmem conhecer toda listagem do Comitê Olímpico Internacional e apenas $2,38 \%$, os riscos e efeitos colaterais do abuso de substâncias consideradas dopantes. Já com relação às punições desportivas por uso de doping e à presença de substâncias consideradas doping em medicamentos prescritos rotineiramente, esses índices elevam-se para 31,55\% e 78,56\%, respectivamente. Mais de $1 / 3$ dos entrevistados já foram solicitados à prescrição de doping, porém a maioria dos profissionais ou negariam a prescrição de substância dopante $(54,16 \%)$ ou encaminhariam o caso aos especialistas $(43,35 \%)$. Quanto ao uso de doping, boa parte $(52,61 \%)$ crê que os atletas o fazem por conta própria. Todos aqueles ligados de certa forma aos jovens devem orientá-lo quanto aos riscos de doping, segundo $53,51 \%$ dos entrevistados, enquanto $18,38 \%$ e $19,82 \%$ achem que essa orientação deve partir dos instrutores/técnicos e dos médi$\cos$, respectivamente. Com relação à advertência da presença de substâncias dopantes nas embalagens e bulas dos fármacos, 67,26\% afirmaram ser ótima iniciativa por prevenir riscos desnecessários. Finalmente, 91,66\% dos entrevistados desejam receber informações sobre doping. Conclui-se que torna-se urgente informar e capacitar os profissionais da saúde quanto ao doping, a fim de orientarem e alertarem os jovens que os procuram na prática diária.

\section{ESTIMATIVA DE LIMIARES DE LACTATO A PARTIR DO TESTE DE LÉGER-BOUCHER}

Autor: Fernando Roberto de Oliveira

Co-autores: Araújo A.S., Lima J.P., Suso J.M.G.

Apresentador: Fernando Roberto de Oliveira

Serviço: Universidade Camilo Castelo Branco/Centre d'Alt Rendiment - Sant Cugat Del Vallés, Barcelona/Universidade Bandeirante de São Paulo

Os Limiares de Lactato (LL), derivados da curva lactato-carga de trabalho, são vulgarmente utilizados como indicadores de capacida- de aeróbia (CAe). Presume-se que uma maior CAe determine uma menor frequiência cardíaca em carga submáxima $\left(\mathrm{FC}_{\text {sub }}\right)$ e que os LL podem ser limitantes do pico de velocidade em um teste progressivo (PV). A partir destas premissas, supõe-se que é possível a estimativa de LL a partir da $\mathrm{FC}_{\text {sub }}$ e PV. Para testar esta hipótese, 64 corredores de nível nacional e internacional, 61 espanhóis e três quenianos (48h e 16m - 21,05 \pm 4,59 anos) foram submetidos, em pista sintética de atletismo, aos testes: a) de Léger-Boucher (TLB), com identificação do PV (corrigido conforme Kuipers e col., 1985) e FC em $15 \mathrm{~km} \cdot \mathrm{h}^{-1}$ $\left(\mathrm{FC}_{15}-\right.$ Polar $\left.^{\circledR}\right)$; b) de 5 x 1.600m $(73,78,83,88,93 \%$ do PV no TLB - Plata e col., 1994), com medida das [la] (Dr. Lange $\left.{ }^{\circledR}\right)$. Critérios utilizados para LL: a velocidade (vel.) com [la] de $4 \mathrm{mmol} \cdot \mathrm{l}^{-1}$ $\left(\mathrm{V}_{4}\right)$; vel. que precede dois aumentos consecutivos, superiores ou iguais à $1 \mathrm{mmol} \cdot \mathrm{l}^{-1}$ (Thoden, 1991 - Vth); vel. correspondente à um segundo aumento de, no mínimo, $0,5 \mathrm{mmol} \cdot \mathrm{l}^{-1}$, maior ou igual ao primeiro aumento (Baldari \& Guidetti, $2000-\mathrm{V}_{\mathrm{Bal}}$ ); vel. com $1 \mathrm{mmol} \cdot \mathrm{l}^{-}$ ${ }^{1}$ acima do menor valor do equivalente [la]/V (Keul e col., 1990 $\mathrm{V}_{\mathrm{Ke}}$ ). Foram elaboradas equações, a partir de análises de regressão múltipla (stepwise), utilizando idade, gênero, $\mathrm{FC}_{15}$ e PV como preditoras dos critérios de LL. Após a obtenção de evidências de validade, em grupos de validação $(n=42)$ e validação cruzada $(n=22)$, os atletas foram agrupados, resultando: $\mathrm{V} 4\left(\mathrm{~km} \cdot \mathrm{h}^{-1}\right)=17,35 \pm 1,69 ; \mathrm{PV}$ $\left(\mathrm{km} \cdot \mathrm{h}^{-1}\right)=19,95 \pm 1,53 ; \mathrm{FC}_{15}(\mathrm{bpm})=168 \pm 15 ; \mathrm{V}_{\text {Bal }}\left(\mathrm{km} \cdot \mathrm{h}^{-1}\right)=16,75$ $\pm 1,63 ; \mathrm{V}_{\mathrm{Th}}=16,34 \pm 1,53 ; \mathrm{V}_{\mathrm{Ke}}\left(\mathrm{km} \cdot \mathrm{h}^{-1}\right)=16,53 \pm 1,66$;

$>\mathrm{V}_{4}\left(\mathrm{~km} \cdot \mathrm{h}^{-1}\right)=11,99+0,57\left(\mathrm{PV}, \mathrm{km} \cdot \mathrm{h}^{-1}\right)-0,38\left(\mathrm{FC}_{15}, \mathrm{bpm}\right) \mathrm{r}=0,88$ $\mathrm{EPE}=0,82 \mathrm{~km} \cdot \mathrm{h}^{-1}$

$>\mathrm{V}_{\text {Bal }}\left(\mathrm{km} \cdot \mathrm{h}^{-1}\right)=7,54+0,67\left(\mathrm{PV}, \mathrm{km} \cdot \mathrm{h}^{-1}\right)-0,28\left(\mathrm{FC}_{15}, \mathrm{bpm}\right) \mathrm{r}=0,89$ $\mathrm{EPE}=0,76 \mathrm{~km} \cdot \mathrm{h}^{-1}$

$>\mathrm{V}_{\mathrm{Th}}\left(\mathrm{km} \cdot \mathrm{h}^{-1}\right)=8,08+0,64\left(\mathrm{PV}, \mathrm{km} \cdot \mathrm{h}^{-1}\right)-0,27\left(\mathrm{FC}_{15}, \mathrm{bpm}\right) \mathrm{r}=0,86$ $\mathrm{EPE}=0,78 \mathrm{~km} \cdot \mathrm{h}^{-1}$

$>\mathrm{V}_{\mathrm{Ke}}\left(\mathrm{km} \cdot \mathrm{h}^{-1}\right)=7,91+0,67\left(\mathrm{PV}, \mathrm{km} \cdot \mathrm{h}^{-1}\right)-0,31\left(\mathrm{FC}_{15}, \mathrm{bpm}\right) \mathrm{r}=0,92$ $\mathrm{EPE}=0,65 \mathrm{~km} \cdot \mathrm{h}^{-1}$

Os resultados corroboraram a hipótese inicial e demonstraram a consistência do modelo de estimativa em diferentes métodos de identificação de LL, recomendando-se estudos adicionais, com a sua aplicação em grupos externos e comparação com outros índices de máximo estado de equilíbrio de lactato.

\section{DETERMINAÇÃO ESTIMATIVA DO GASTO ENER- GÉTICO EM JOGADORES DE FUTEBOL DURANTE TREINAMENTO UTILIZANDO-SE PARÂMETROS ERGOESPIROMÉTRICOS}

Autor: Alessadra Favano

Co-autores: Favano A., Pedrinelli A., Silva P.R.S., Teixeira A.A.A., Angelini F.J., Facci E.S., Galotti R., Gondo M.M., Greve J.M.D'A., Amatuzzi M.M.

Serviço: Laboratório de Estudos do Movimento do Instituto de Ortopedia e Traumatologia (IOT) do HCFMUSP

Introdução: $\mathrm{O}$ futebol é uma modalidade esportiva que demanda atividade física combinando exercício intermitente com graus variados de intensidades realizados continuamente durante a partida. Objetivo: Calcular o gasto energético individual de cada atleta utilizando-se os limiares ventilatórios um $\left(\mathrm{LV}_{1}\right)$ e dois $\left(\mathrm{LV}_{2}\right)$ como marcadores representativos dessas intensidades utilizadas durante o treinamento. Material e métodos: Foram avaliados 21 futebolistas profissionais, com média de idade de $22 \pm 3$ anos, peso $=70 \pm 3 \mathrm{~kg}$ e que foram submetidos a avaliação cardiorrespiratória e metabólica 
utilizando-se um analisador de gases computadorizado (SensorMedics, Vmax 29c, EUA). O cálculo do gasto energético em Kcal nas intensidades determinadas $\left(\mathrm{LV}_{1}=\right.$ moderada $\mathrm{LV}_{1}+\mathrm{LV}_{2} / 2=$ intensa e $\mathrm{LV}_{2}=$ muito intensa) foi realizado pela fórmula do American College of Sports Medicine $\left[\mathrm{Kcal} / \mathrm{min}=\mathrm{n}^{\circ}\right.$ de met's x 3,5 x peso $\left.[\mathrm{kg}]\right) /$ 200]. Resultados:

\begin{tabular}{|l|c|c|c|c|c|}
\hline \multicolumn{1}{|c|}{ Intensidades } & $\begin{array}{c}\mathrm{VO}_{2} \\
(\mathrm{ml} / \mathrm{kg} / \mathrm{min})\end{array}$ & $\begin{array}{c}\mathrm{N}^{\circ} \\
(\mathrm{met} \text { 's }\end{array}$ & $\begin{array}{c}\mathrm{Kcal} \\
(\mathrm{min})\end{array}$ & $\begin{array}{c}\mathrm{Kcal} \\
\text { (treino) }\end{array}$ & $\begin{array}{c}\text { Tempo/Treino } \\
(\mathrm{min})\end{array}$ \\
\hline $\mathrm{LV}_{1}$ & $35 \pm 5$ & $10 \pm 3$ & $12,2 \pm 4$ & $610 \pm 31$ & 50 \\
\hline $\mathrm{LV}_{1}+\mathrm{LV}_{2} / 2$ & $42 \pm 3$ & $12 \pm 3$ & $14,7 \pm 4$ & $441 \pm 35$ & 30 \\
\hline $\mathrm{LV}_{2}$ & $50 \pm 3$ & $14 \pm 4$ & $17,1 \pm 3$ & $171 \pm 41$ & 10 \\
\hline
\end{tabular}

Obs.: Os dados representam média e desvio-padrão.

Conclusão: Os resultados demonstraram que a ergoespirometria é uma metodologia de grande importância não só para a verificação de marcadores de performance atlética, mas fornece dados que também podem ser canalizados para o controle das necessidades nutricionais através da quantificação do gasto calórico durante treinamento. Consumo de Oxigênio de Pico (VO2pico) e o Limiar Ventilatório Dois (LV2) como Preditores de Tolerância ao Exercício em Jogadores de Futebol.

\section{CONSUMO DE OXIGÊNIO DE PICO (VO2PICO) E O LIMIAR VENTILATÓRIO DOIS (LV2) COMO PREDI- TORES DE TOLERÂNCIA AO EXERCÍCIO EM JOGA- DORES DE FUTEBOL}

Autor: Paulo Roberto S. Silva

Co-autores: Silva P.R.S., Fonseca A.J., Teixeira A.A.A., Facci E.S., Galotti R., Angelini F.J., Gondo M.M., Favano A., Pedrinelli A., Greve J.M.D.' A., Amatuzzi M.M.

Apresentador: Paulo Roberto S. Silva

Serviço: Laboratório de Estudos do Movimento do Instituto de Ortopedia e Traumatologia (IOT) do HCFMUSP

Introdução: O consumo de oxigênio de pico (VO2pico) e o limiar anaeróbio determinado por troca gasosa ventilatória, são dois parâmetros utilizados com frequiência para classificar o nível de aptidão espirométrica em indivíduos com diferentes graus de capacidade funcional. Objetivo: verificar a importância do VO2pico e do limiar ventilatório dois (LV2) como preditores de tolerância ao exercício em jogadores de futebol. Material e métodos: Foram avaliados 45 futebolistas, todos do sexo masculino, com média de idade de 21,0 ? 4,7 anos. Todos os atletas eram pertencentes ao Departamento de Futebol de um clube da 1 1 a divisão da Cidade de São Paulo e foram submetidos à avaliação cardiorrespiratória e metabólica, utilizandose analisador metabólico de gases (modelo CPX/D, MedGraphics, EUA) acoplado a eletrocardiógrafo (modelo Personal, Marquette, EUA), ambos os sistemas computadorizados. A determinação da capacidade física máxima foi verificada em esteira rolante (modelo ATL - 10200, Inbramed, BRA) utilizando-se protocolo escalonado contínuo com inclinação fixa de 3\%. Resultados: $\mathrm{VO} 2$ pico $=59,5$ ? 4,4ml.kg.-1 min-1; VO2-LV2 = 51,6 ? 4,3ml.kg-1.min-1; \%VO2picoLV2 = 87 ? 5; VCLV2 = 13,7 ? 0,8km.h-1; TTMAX. = $1028 ?$ 132s.; TT-LV2 = 748 ? 90s. Análise de regressão linear demonstrou correlação positiva entre o TTMAX. e o VO2pico. ao exercício $(r=0,71$; $\mathrm{p}<0,05)$; entre o TTMAX. e a velocidade de corrida no LV2 $(\mathrm{r}=$ 0,53; $\mathrm{p}<0,0001)$; entre o TTMAX e o TT-LV2 $(\mathrm{r}=0,50 ; \mathrm{p}<0,0001)$ e entre o VO2pico e o VO2-LV2 $(r=0,69$; $p<0,05)$. Conclusão: $O$ desenvolvimento da potência aeróbia associado ao aumento de con- sumo de oxigênio no LV2, devem ser sistematicamente verificados durante exercício máximo para melhor avaliar o nível de aptidão física em jogadores de futebol.

\section{LIMIAR ANAERÓBIO E VELOCIDADE MÉDIA DO TESTE DE COOPER}

Autor: César C. Cal Abad

Co-autores: Barros R.V., Barros L.F.P., Kiss M.A.P.D.M.

Apresentador: César C. Cal Abad

Serviço: Uniban - São Paulo

Introdução: Atletas de atividade aeróbia (meio-fundistas e fundistas) com maiores velocidades no limiar anaeróbio (LAN) em protocolo escalonado, teoricamente, também mantêm velocidade média mais elevada durante atividade contínua. O objetivo deste estudo foi verificar se em atletas de atividade intermitente, existe comportamento semelhante para estas variáveis. Material/casuística e métodos, ou caso clínico: Para isso, 15 atletas de futsal (24,5 $\pm 3,7$ anos), de uma equipe paulista que disputou o campeonato estadual, realizaram num período de 5 dias, dois testes de campo: um progressivo (Léger \& Boucher, 1988) e outro contínuo (Cooper, 1968). No teste progressivo, determinamos a velocidade do LAN pelo ponto de deflexão da FC (Conconi et. al., 1982) e no teste contínuo, calculamos a velocidade média atingida pela distância obtida durante 12 minutos. Resultados/conclusão: No teste progressivo, a velocidade equivalente ao PDFC foi de $11,6 \pm 0,5 \mathrm{~km} . \mathrm{h}-1$ (encontrada em $84 \%$ da amostra) e no teste de 12 min a velocidade média foi de $15,0 \pm$ 0,91km.h-1. Para análise estatística foi utilizada a correlação de Pearson que apresentou um $r=-0,32(p>0,05)$. Como a velocidade do PDFC, observada em teste de Leger, não se correlacionou com a velocidade média do teste de 12 minutos para atletas de futebol de salão, concluímos que nosso enunciado não se sustentou para esta população. Talvez por possíveis diferenças das características biomecânicas de corrida entre atletas aeróbios e atletas de atividades anaeróbias e intermitentes ou a escolha dos protocolos dos testes, bem como o método de detecção do LAN, não foram adequados. Para averiguação deste comportamento, sugerimos a realização de novos estudos com outras populações e/ou outros protocolos.

\section{VARIAÇÃO DOS PARÂMETROS DE BIOIMPEDÂN- CIA COM A ATIVIDADE FÍSICA EXTENUANTE}

Autor: Adilson A. Dias

Co-autores: Monreal M.A., Formiga F.B., Monreal M.A., Cisternas J.R., Gajardo J.R.C., Varga J., Monte O.

Apresentador: Máira Monreal

Serviço: Faculdade de Ciências Médicas da Santa Casa de São Paulo

Introdução: Com o crescimento da necessidade de uma melhor avaliação nas mudanças fisiológicas ocasionadas pelo exercício físico, a bioimpedância parece ser um eficiente método. O objetivo deste trabalho é analisar de maneira direta os parâmetros de impedância (corporal e segmentar) em atletas jovens do sexo masculino e a variação destes parâmetros com o padrão de treinamento e a atividade física extenuante. Material/casuística e métodos, ou caso clínico: Para isso, 60 atletas foram divididos em dois grupos: praticantes de atletismo e atividade física sem modalidade específica. Mediu-se resistência e reatância capacitiva de corpo total e membros superior 
e inferior antes e depois do exercício físico com o aparelho BIA110A, R.J.L. Systems Inc. utilizando a técnica tetrapolar. Comparou-se estatisticamente os resultados através do Teste de Bartlett para análise da variância, os Testes-t de Student pareado e não-pareado, e o Teste de Mann-Whitney. Resultados/conclusão: Os resultados serão apresentados em: média (desvio padrão). O peso variou: Grupo 1: repouso: $67,4(8,5) \mathrm{kg}$, pós-exerc.: $66,4(8,5) \mathrm{kg}$. Grupo 2 : repouso: $67,6(7,4) \mathrm{kg}$, pós-exerc.: $66,6(7,4) \mathrm{kg}$. Os valores a seguir são de corpo total. A variação da resistência foi de: Grupo 1: repouso: 437,7 (56,7)ohms, e pós-ativ: 460,9 $(41,5)$ ohms, Grupo 2: repouso: 454,1 $(52,2)$ ohms, pós-atividade: $465,8(35,9)$ ohms. Reatância capacitiva: Grupo 1: repouso: $65,1(12,7) \mathrm{ohms}$, pós-ativ: 60,9 $(8,1)$ ohms, no Grupo 2: repouso: $64,0(5,4)$ ohms, pós-ativ: 65,3 $(4,7)$ ohms, e ângulo de fase: Grupo 1: repouso: $7,7(1,1)^{\circ}$ pós-ativ.: $7,7(0,6)^{\circ}$, Grupo 2: repouso: $8,1(0,9)^{\circ}$, pós-ativ: $8,0(0,5)^{\circ}$. Abaixo os parâmetros de impedância de membro inferior direito: Resistência: Grupo 1: repouso: 257,9 (38,3)ohms, pós-ativ: 239,2 (26,0)ohms (*), Grupo 1: repouso: 228,9 (20,5)ohms, pós-ativ: 228,1 (20,2)ohms, reatância capacitiva: Grupo 1: repouso: 38,5 (2,3)ohms, pós-ativ.: 39,8 (2,2)ohms, Grupo 2: repouso: 32,7 (2,9)ohms, pós-ativ: 32,2 $(3,5) \mathrm{ohms}$, e ângulo de fase: Grupo 1: repouso: $8,6(2,0)^{\circ}$, pós-ativ.: $9,4(3,7)^{\circ}$, Grupo 2: repouso: 8,2 $(0,6)$, pós-ativ: 8,0 $(0,7)^{\circ}\left(^{*}\right) * \mathrm{p}<$ 0,05 . Houve diferença significativa apenas na reatância capacitiva após o exercício e nas medidas de resistência e reatância em repouso entre os grupos. Após atividade física houve diferença significativa na resistência e na reatância de membros inferiores. Concluiu-se que os atletas praticantes de atletismo tiveram uma constância maior nos parâmetros do que aqueles com atividade de educação física e que a bioimpedância pode ser aplicada logo após o exercício quando os examinados possuírem atividade física regular, podendo ser, portanto usada na avaliação do estresse físico.

\section{COMPARAÇÃO DO CONSUMO DE OXIGÊNIO EN- TRE O PRIMEIRO E O TERCEIRO MINUTO EM TES- TE PROGRESSIVO}

Autor: Melina Aguiar

Co-autores: Barros R.V., Abad C.C.C., Barros L.F.P., Routman K.S., Kiss M.AP.D.M.

Apresentador: Melina Aguiar

Serviço: USP

Introdução: Os testes laboratoriais vêm sendo utilizados como instrumento de avaliação e prescrição de treinamento. Para amenizar os erros de interpretação e aumentar a precisão dos dados mensurados, a escolha do protocolo é de fundamental importância, pois dependendo da variável avaliada no teste, o tempo de manutenção da carga pode influenciar o valor obtido. Alguns estudos (Bogaard et al., 1996; Whipp \& Ozyener, 1998), comparando teste escalonado e de rampa, observaram que o valor do consumo de oxigênio (VO2) relativo à carga, depende da intensidade e do protocolo utilizado. $\mathrm{O}$ objetivo deste trabalho foi verificar a diferença do VO2 entre o final do primeiro e do terceiro minuto em cargas submáximas num teste progressivo. Material/casuística e métodos, ou caso clínico: Para isso, 42 chineses, jogadores de futebol (entre 14 e 19 anos, massa corporal de 67,8 ? 7,1 e estatura de 177,9 ? 6,2), após realizarem as medidas antropométricas (padrão Lohman et al., 1988), foram submetidos ao teste progressivo na esteira, cujo protocolo constou de velocidade inicial $7,1 \mathrm{~km} / \mathrm{h}$, incrementos de aproximadamente $1,4 \mathrm{~km} /$ $\mathrm{h}$ a cada 3 minutos, e intervalos de 30 segundos entre as cargas (Heck, 1985). O VO2 foi obtido respiração-a-respiração por medida direta pelo aparelho K4b2 $\left(\right.$ Cosmed $\left.^{\circledR}\right)$. Para tratamento estatístico foi utilizada a média do VO2 dos 10 segundos finais do primeiro e terceiro minuto de cada carga. Para comparação das médias foi aplicado o teste t-Student (amostras correlacionadas) e a correlação de Pearson. Resultados/conclusão:

Tabela 1 - Médias de consumo de oxigênio no 1? e 3 ? min Velocidade $(\mathrm{km} / \mathrm{h}) 1^{\circ}$ minuto $3^{\circ}$ minuto $7.127,3$ ? 4,2 29,2 ? 3,6* 8.6 33,7 ? 4,1 36,6 ? 3,8*10.0 37,8 ? 4,1 41,5 ? 4,5* $11.441,6$ ? 4,1 46,3 ? 4,7* 12.8 44,6 ? 4,3 49,4 ? 5,1*14.2 47,7 ? 4,8 53,0 ? 5,9** diferença significativa $(\mathrm{p}<0,01)$

Tabela 1 - Médias de consumo de oxigênio no 1? e 3 ? min Velocidade $(\mathrm{km} / \mathrm{h}) 1^{\circ}$ minuto $3^{\circ}$ minuto $7.127,3$ ? 4,2 29,2 ? 3,6* 8.6 33,7 ? 4,1 36,6 ? 3,8* $10.037,8$ ? 4,1 41,5 ? 4,5* $11.441,6$ ? 4,1 46,3 ? 4,7* $12.844,6$ ? 4,3 49,4 ? 5,1* $14.247,7$ ? 4,8 53,0 ? 5,9** diferença significativa $(\mathrm{p}<0,01)$

Tabela 1 - Médias de consumo de oxigênio no 1? e 3 ? min Velocidade $(\mathrm{km} / \mathrm{h}) 1^{\circ}$ minuto $3^{\circ}$ minuto $7.127,3$ ? 4,2 29,2 ? 3,6* 8.6 33,7 ? 4,1 36,6 ? 3,8*10.0 37,8 ? 4,1 41,5 ? 4,5* 11.4 41,6 ? 4,1 46,3 ? 4,7* 12.8 44,6 ? 4,3 49,4 ? 5,1*14.2 47,7 ? 4,8 53,0 ? 5,9** diferença significativa $(\mathrm{p}<0,01)$

Os resultados indicam que apesar da alta correlação entre primeiro e terceiro minutos em todas as cargas (entre 0,77 e 0,92 ), as diferenças entre as médias foram significativas (Tabela 1). Concluímos que a unidade de tempo de um minuto parece não ser suficiente para alcançar o equilíbrio do VO2 em cargas submáximas, tanto em velocidades de menor intensidade quanto de maior.

\section{ERGOESPIROMETRIA EM ATLETAS DE BASQUETE- BOL EM CADEIRAS DE RODAS (BCR) EM ESTEIRAS E CAMPO}

Autor: Elizabete Tsubomi Saito

Co-autores: Routman K., Degaki E., Mattos E., Yazbeck P., Batistella L., Kiss M.A.P.D.M.

Apresentador: Elizabete Tsumobi Saito

Serviço: USP

Introdução: Atualmente observa-se um número crescente de deficientes físicos envolvidos em atividades esportivas competitivas. $\mathrm{Na}$ literatura encontra-se poucas informações sobre avaliações de consumo de oxigênio em situações mais semelhantes à de campo em atletas portadores de deficiências físicas. O objetivo desse ensaio foi comparar os valores de Consumo de oxigênio máximo (VO2 máx) em atletas de basquetebol em cadeira de rodas em esteira e em campo. Material/casuística e métodos, ou caso clínico: Dois atletas de basquetebol em cadeira de rodas, sendo um portador de lesão medular nível motor C8 (LM), e outro portador de seqüela de poliomielite (Pólio), com comprometimento de MSD e MMII. Ambos possuem a mesma classificação funcional BCR (classe funcional 1). Os atletas foram submetidos a teste de campo de Lerger adaptado, utilizando o espirômetro K4b2 (Cosmed) e teste ergoespirométrico de laboratório (EL), utilizando a esteira Imbrasport modelo Millenium rodas (sistema de monitorização ergo PC Elite Micromed), e espirômetro modelo Teem 100 seguindo o protocolo cadeira de rodas padronizado pela equipe de cardiologia da DMR. Resultados/conclusão: 
Obtivemos valor VO2 máx no teste de campo Lerger no atleta LM de $31,3 \mathrm{ml} / \mathrm{kg}$.min e no atleta com seqüela de pólio $29,7 \mathrm{ml} / \mathrm{kg}$.min. No teste ergoespirométrico de laboratório obtivemos valor VO2 máx de $25 \mathrm{ml} / \mathrm{kg}$.min no atleta $\mathrm{LM}$ e de $27,9 \mathrm{ml} / \mathrm{kg}$.min no atleta com seqüela de pólio. Discussão e conclusão: Obtivemos valores de VO2 máx maiores no teste em campo tanto no atleta LM como no atleta com seqüelas de pólio. O resultado do EL teve valores semelhantes no atleta LM e com sequielas de pólio e com valores baixos comparados a testes de pessoas não portadoras de deficiência física. Isso pode ser explicado devido ao menor envolvimento de massa muscular característico da modalidade esportiva (BCR) e ou pelo fato desses atletas terem menor quantidade de músculo esquelético ativo para consumir $\mathrm{O} 2$. O atleta LM teve VO2 máx $=31,3 \mathrm{ml} / \mathrm{kg}$. min no teste de campo (Lerger) e o atleta com seqüela pós-pólio VO2 máx = $29,7 \mathrm{ml} / \mathrm{kg}$.min. Provavelmente essa diferença deve-se ao fato do VO2 máx do atleta LM ter sido obtido quando o mesmo entrou em fadiga e do atleta com seqüela pós-pólio quando o mesmo não conseguia atingir a velocidade constante.

\section{INCIDÊNCIA DE LESÕES DO PÉ E TORNOZELO NA PRÁTICA DESPORTIVA RECREACIONAL}

Autor: Alexandre de Paiva Luciano

Co-autores: Lara L.C.R., Franco Filho N., Vargas A.R.

Apresentador: Alexandre de Paiva Luciano

Serviço: Serviço de Ortopedia e Traumatologia da Universidade de Taubaté-SP

Os autores apresentam informações retrospectivas sobre a incidência, tipo e extensão das lesões ocorridas no pé e/ou tornozelo como resultado da prática esportiva recreacional. $\mathrm{O}$ estudo foi realizado durante o período de junho de 2000 a janeiro de 2001 no Pronto Socorro Municipal de Taubaté S.P. e clínica particular do autor. Foram atendidos e examinados, pelos próprios autores, 108 pacientes sendo 100 pacientes do sexo masculino e 8 pacientes do sexo feminino, com queixa de trauma e/ou dor em pé e/ou tornozelo após a prática de esportes recreacionais. A média de idade do sexo masculino foi de 24,53 anos e do sexo feminino foi de 15,75. A avaliação foi realizada através de um protocolo de pesquisa, que continha as variáveis de idade, sexo, cor, diagnóstico estabelecido, conduta realizada e o tipo de esporte recreativo envolvido. A lesão mais encontrada no pé e tornozelo foi a entorse, acometendo principalmente o complexo ligamentar lateral, com maior incidência no grau II. O futebol de salão foi o maior causador de lesões do pé e tornozelo no sexo masculino ( 35 casos). O futebol de campo foi o maior causador de lesão no sexo feminino (4 casos).

\section{LESÕES NA GINÁSTICA AERÓBICA DE COMPETI- ÇÃO EM ATLETAS BRASILEIROS}

Autor: Maurício Ramalho Romeiro

Co-autor: Ghirotto F.M.S.

Apresentador: Maurício Ramalho Romeiro

Serviço: Uni-FMU - Centro Universitário das Faculdades Metropolitanas Unidas

A Ginástica Aeróbica foi criada em 1969 por Jacki Sorensen que tinha como atividade preparar coreografias especiais para um programa de condicionamento físico pela TV destinado a esposas de militares americanos baseados em Porto Rico, ela não imaginava que estava dando início a um "fenômeno" que envolveria milhões de entusiastas. Samulki, em 1994, descreveu a Ginástica Aeróbica como uma rotina de passos básicos do ser humano acrescida de algumas variações dos movimentos tradicionais da dança, somados a exercícios calistênicos, incorporados à música. A Ginástica Aeróbica pode causar a redução de gordura corporal, melhorar a potência aeróbica, aumentar a força dos membros inferiores, melhorar a agilidade e flexibilidade geral do corpo humano, e ainda o desempenho psicossocial de seus praticantes, no entanto, diversos estudos tem mencionado incidências de lesões que podem trazer prejuízos temporários ou até mesmo permanentes. Na década de oitenta surgiu a versão competitiva da Ginástica Aeróbica, tornando-a um esporte com alto nível de exigências físicas e psíquicas com elementos variados em sua rotina, compostos por: coreografia, criatividade, força, resistência, flexibilidade, carisma e uma perfeita interpretação da música através do corpo e do movimento. Na Ginástica Aeróbica é grande a complexidade dos movimentos, sendo as articulações mais exigidas: joelhos, escápula-umeral, coxo femoral, cúbitos, punhos e tornozelos. Apesar da Ginástica Aeróbica ser uma prática conhecida e freqüente nas academias de ginástica, sua variante competitiva ainda não é suficientemente conhecida. Entretanto, os agravos decorrentes desta prática têm sido constatados e estudados em diferentes níveis. Nesse sentido, o objetivo deste estudo foi identificar e revelar as lesões mais frequientes entre os atletas de alto nível da Ginástica Aeróbica de Competição, com a realização de coleta de dados realizada em 71 atletas, sendo 47 do sexo feminino e 24 do sexo masculino. Metodologicamente, adotou-se o inquérito de morbidade referida, (Ghirotto, 1992) no qual o instrumento questionário foi validado e aplicado. Desse modo, os resultados encontrados na população estudada mostram que $58 \%$ dos atletas do sexo masculino reportaram lesões durante o período de tempo em que praticaram esta atividade, sendo que o tempo médio de prática do esporte pelos atletas foi de 04 anos para $28 \%$ deles. Os resultados mostram, ainda, que $43 \%$ dos atletas apresentaram de um a dois tipos de lesões e $14 \%$ apresentaram três tipos; cabe ressaltar, no entanto, que $62 \%$ tiveram reincidência das referidas lesões. Os tipos de lesões mais freqüentes foram: tendinite $(50 \%)$, estiramento $(21 \%)$ e entorse $(13 \%)$ e as estruturas mais lesionadas foram: punho $(25 \%)$, posterior de coxa $(21 \%)$, seguidos das articulações do joelho e tornozelo com $13 \%$, respectivamente. Já as atletas femininas apresentaram um índice de $62 \%$ de lesões durante o período de tempo em que praticaram Ginástica Aeróbica de Competição, sendo que o tempo médio de prática do esporte pelas atletas foi de 03 anos para $21 \%$ delas. Os resultados mostram que 55\% apresentaram um tipo de lesão, $28 \%$ dois tipos de lesões e $10 \%$ três tipos de lesões, sendo que 59\% apresentaram reincidência de lesões. Sua tipologia concentrou-se em: tendinite (34\%), distensão (14\%) e entorse (12\%), e as estruturas mais lesadas foram: tornozelos $(25 \%)$, punhos (17\%) e os joelhos (14\%). Podemos concluir então que a tendinite é a lesão de maior ocorrência, em ambos os sexos, cabendo ressaltar, que atletas masculinos apresentam maior incidência no punho, enquanto que nas atletas femininas no tornozelo. Apesar desta ser uma modalidade esportiva recente, devemos alertar os treinadores e atletas para a necessidade de medidas preventivas e curativas em relação as lesões osteomusculares, evitando riscos em treinamentos e campeonatos, e ainda permitindo a criação de melhores métodos de prática desta atividade que encanta praticantes e expectadores no mundo inteiro. 


\section{AVALIAÇÕES DO ATENDIMENTO DA EQUIPE MÉ- DICA MULTIDISCIPLINAR NA MARATONA INTER- NACIONAL DE SÃO PAULO}

Autor: Samir Salim Daher

Co-autores: Baptista C.A., Freitas A., Terreri A.S., Kuhlmann

G.G., Fernandes A.O., Martins M.

Apresentador: Samir Daher

Serviço: Hospital do Servidor Público Estadual

Objetivo: A Maratona é uma corrida com um percurso de 42,195km que segue um padrão de organização mundial. Atualmente é uma competição popular com atletas participantes profissionais ou não, com idades variadas, e de várias formações. O objetivo deste trabalho foi relacionar as ocorrências médicas na VII Maratona Internacional de São Paulo, com o aspecto organizacional da equipe médica e multidisciplinar. Material/casuística e métodos, ou caso clínico: Na última Maratona Internacional de São Paulo estiveram presentes 226 profissionais da área de saúde, distribuídos em 14 postos de atendimento médico durante o percurso a cada $3 \mathrm{~km}$, e na chegada. Do total, 44 eram médicos, 8 enfermeiros, 52 auxiliares de enfermagem, 50 fisioterapeutas, 28 motoristas, 20 padioleiros, 13 monitores com motocicleta e 11 coordenadores. Para toda a prova foram requeridas: 3 ambulâncias de suporte avançado (AUTI), 22 ambulâncias de suporte básico (ASB), 12 motocicletas, 4 vans, 3 ônibus-prego (acompanham os participantes), 1 posto de atendimento fixo, no $\mathrm{km} 21$ (posto 7). Em cada posto de atendimento ficou a disposição: 1 ASB com motorista e enfermeiro, 1 médico e 2 fisioterapeutas, exceto o posto 7 - km 21 que continha: 1 AUTI, 2 ASB, 3 médicos, 4 enfermeiros, 4 fisioterapeutas. Foram solicitados questionários aos atletas antes e depois da prova, com os seguintes itens: idade, sexo, cor, orientação profissional para a corrida, objetivo de estar participando da prova e a forma de treinamento. Todos os profissionais que atendessem a alguma ocorrência estavam orientados a relacionar os dados em uma planilha. Resultados/conclusões: Estiveram inscritos na prova 8.920 atletas e iniciaram 6.950, sendo que 6.004 terminaram a prova. Foram entrevistados 832 atletas; idade média do foi de 38 anos, com mínimo de 16 e máximo de 79 anos; $61 \%$ (507) brancos, $87 \%$ (723) sexo masculino; 51\% (424) dos atletas correram a prova sem qualquer orientação médica. Dos participantes $68 \%$ (565) gostariam de melhorar o tempo em relação ao ano anterior ou apenas por lazer; 55\% (457) já correram mais de uma vez a maratona. O total de atendimentos realizados foram 404, sendo: 290 durante o percurso e 114 na chegada. As ocorrências clínicas mais comuns foram: câimbras em 24 atletas $(6,2 \%)$, mal estar indefinido em 28 participantes (7\%), cansaço em $270(67,8 \%)$ e dor músculo-esquelética em 76 (19\%). Tempo médio de duração da corrida foi 4 h e 30 min. Como conclusões: 1) Foi satisfatório a estrutura médica. 2) Necessidade de um posto de atendimento médico imediatamente após a chegada, se faz necessário, pois na última prova este posto ficou a uma distância superior a 250 metros, sendo necessário a constante remoção dos atletas pelos padioleiros. 3) A participação de equipe multidisciplinar notadamente de fisioterapeutas muito contribuiu para uma melhor adequação no atendimento. 4) Incentivar que os participantes procurem orientação especializada para a Maratona. 5) As principais lesões músculo-esqueléticas foram nos membros inferiores, sendo: coxa-virilha em 24 atletas (31\%), joelho em 17 participantes (22\%), 20 queixas de dor na panturrilha $(26 \%)$ e 11 , no tornozelo (15\%).

\section{ESTUDO COMPARATIVO DAS LESÕES MAIS CO- MUNS DOS ATLETAS DA SELEÇÃO BRASILEIRA DE HANDEBOL, ENTRE JOGOS E TREINOS. ACOMPA- NHAMENTO POR DOIS ANOS}

Autor: Samir Salim Daher

Apresentador: Samir Salim Daher

Serviço: Hospital do Servidor Público Estadual-SP

Objetivo: Durante o período de 1999 a 2001, foram acompanhados os atletas das Seleções Brasileiras de Handebol Masculino Adulto e Júnior, nos campeonatos Sul Americano, Pan-Americano e Mundial, além das fases de treinamento e amistosos. O objetivo deste trabalho foi relacionar as queixas ortopédicas e as lesões mais comuns do Handebol de alto nível, comparando as fases em que as equipes se encontravam: treinamento ou competição. Material/casuística e métodos, ou caso clínico: O Handebol é um esporte muito popular e apreciado em quase toda a Europa há quase um século e, o Brasil figura como uma das principais equipes das Américas na categoria masculina e talvez, a principal equipe, na feminina, além de ter sido considerado o país que mais evoluiu no esporte, pela IHF (International Handebol Federation), órgão máximo da entidade, em 2000. Durante esse período, as fases de treinamento e competição das Seleções Brasileiras Adulto e Júnior de Handebol somaram aproximadamente 671 horas, sendo $92 \%$ (623hs) de treinamento e $25 \%$ (48hs) de jogos, incluindo amistosos. Para cada fase de treinamento e competição eram convocados 16 atletas, e as seleções mantinham quase sempre a mesma base selecionada, o que facilitou o acompanhamento médico. Porém, a cada convocação, era feita uma nova avaliação através de questionário simples e exame físico. Os treinamentos das Seleções eram sempre realizados em dois períodos equivalentes a aproximadamente $7 \mathrm{hs}$ de treino/dia para os adultos e $5 \mathrm{hs}$, para os juniores. O acompanhamento médico foi realizado durante os treinos e jogos, e nas concentrações dos atletas durante o período de repouso, individualmente, duas vezes ao dia. Foram relacionadas as principais queixas de cada atleta que necessitaram de algum tipo de tratamento: medicamentoso, fisioterapêutico, afastamento do treino ou competição. As lesões ocorridas durante os jogos e treinos eram anotadas em função: local do corpo, primeiro diagnóstico, causa da lesão, tipo de tratamento e afastamento da competição. As queixas relacionadas foram feitas por atletas e o mesmo diagnóstico, em cada etapa de treinamento ou jogo, era considerado uma única vez. Resultados/conclusões: O total de queixas registradas foi de 128 , considerando-se cada convocação, podendo repetir os atletas analisados. Os principais diagnósticos analisados após os jogos foram: contusão $67 \%$ (85), dor muscular 15\%(19), tendinite 9\% (12), entorse $9 \%$ (12). As principais regiões acometidas foram: ombro $20 \%$ (25), cotovelo 8\% (10), punho e mão $12 \%$ (15); coxa 21\% (26), joelho e tornozelo $6 \%$ (7). As queixas ocorridas após os treinos foram: dores musculares $-38 \%$ (48), tendinites - 34\% (43), contusões $20 \%$ (25), entorses $-6 \%$ (7). As principais regiões acometidas foram: ombro $15 \%$ (19), punho e mão 5\% (6); coxa 4\% (5), joelho $36 \%$ (46), tornozelo $4 \%$ (5). Não foi analisada nenhuma fratura, luxação ou outro problema ortopédico que afastasse o atleta por mais de 48 horas. Como conclusões: Quando se acompanha atleta de alto nível, é fundamental conhecer por completo a modalidade esportiva, facilitando assim, a compreensão das lesões típicas do esporte e seu tratamento. As diferenças entre as lesões ocorridas nos treinamentos e competição foram diferentes, principalmente pelo excesso de re- 
petições realizadas no treino, e no contato físico, durante o jogo. Os membros superiores são mais afetados durante os jogos, e os membros inferiores, nos treinamentos. Apesar de não ter sido constatada nenhuma lesão cirúrgica neste período, sempre estar ciente das lesões antigas de cada atleta, bem como cirurgias anteriores realizadas.

\section{MIOCARDIOPATIA ISOLADA NÃO COMPACTADA DIAGNOSTICADA EM UM JOVEM JOGADOR DE FU- TEBOL}

Autor: Marcelo Regazzini

Co-autores: Martin V., Degaki E., Salemi V.M.C., Mady C., Kiss M.A.P.D.M.

Apresentador: Marcelo Regazzini

Serviço: *LADESP - DE - EEFE - CENESP - USP: Laboratório de Desempenho Esportivo do Departamento de Esporte da Escola de Educação Física e Esporte da Universidade de São Paulo, Centro de Excelência Esportiva; ** CG-INCOR - FM - USP: Cardiologia Geral do Instituto do Coração da Faculdade de Medicina da Universidade de São Paulo

A não compactação isolada do miocárdio ventricular é uma cardiopatia congênita rara resultando em uma interrupção na embriogênese normal do endomiocárdio (ELSHERSHARI H, OKUTAN V, CELIKER A., 2001; SHAH CP, NAGI KS, THAKUR RK, BOUGHNER DR, XIE B., 1998; VICTOR S, NAYAK VM, RAJASINGH R., 1999). Presume-se ser originária de uma anormalidade no desenvolvimento da evolução miocárdica resultando em um miocárdio de aspecto esponjoso (HALBERTSMA FJ, VAN'T HEK LG, DANIELS O., 2001). Durante o desenvolvimento inicial do coração, a estrutura esponjosa primária persiste relacionada a um bloqueio da compactação (NEUDORF UE, HUSSEIN A, TROWITZSCH E, SCHMALTZ AA, 2001). O coração inicialmente se apresenta como uma trama trabecular onde os espaços intertrabeculares se comunicam com as câmaras e a medida que evolui, ocorre uma condensação, uma compactação; reduzindo-as a capilares. Define-se como uma anormalidade da morfogênese endomiocárdica, formando uma fibra frouxa entrelaçada durante a vida intra-uterina, usualmente diagnosticada na população pediátrica, em ambos os sexos, podendo haver recorrência familiar e geralmente associada a outras malformações estruturais congênitas do coração. $\mathrm{O}$ fato de ser isolado, é devido a não associação com outras patologias, o que torna a apresentação mais rara ainda. PEIXOTO, CA.; KUNIYOSHI, R.; VALADÃO, W.; ELIAS, J. 2000. Um jovem, F.D.N., de 15 anos de idade, jogador de futebol juvenil proveniente de um clube de futebol de São Paulo, procurou os nossos serviços para uma avaliação clínico-cardiológica sugerida por indicação do treinador, devido queixas de desconforto torácico, dor precordial, tonturas e palpitações aos grande esforços, sendo comumente solicitado parar para se recuperar durante o treinamento, com evolução progressiva desde há um ano quando ingressou nesta atividade. HPMA Sem antecedentes durante a gravidez, parto normal, amamentação até os 6 meses, vacinações completas, doenças de infância sem intercorrências. Aos 3 anos apresentou início de asma brônquica de fundo alérgico (SIC), que quando desencadeada por atividade física provocava cianose e sudorese intensa. Aos 6 anos apresentou uma crise convulsiva pós traumática craniencefálica isolada e tratada convenientemente. Iniciou atividades esportivas específicas aos 10 anos em natação e posteriormente em artes marciais, onde se destacou, chegando a faixa-preta e conquistando vários títulos. Há um ano foi admitido no futebol, como atacante. Com o início dos treinamentos, em fase de maior intensidade das cargas de trabalho, observou que aos grandes esforços apresentava dor no peito difusa de pequena intensidade, palpitações arrítmicas, dispnéia e as vezes tonturas e tosse seca; negando chiado no peito, náuseas ou vômitos, síncopes, escotomas visuais ou outros concomitantes; que melhorava em 3 a 4 minutos de recuperação ativa, voltando a treinar. Evoluiu com agravamento dos sinais e sintomas descritos, ocorrências mais freqüentes e necessitando de maior tempo de recuperação sendo necessário solicitar ao treinador a sua substituição.

AF: Pais, avós e irmão sem antecedentes, Tio paterno com história de morte súbita. Alguns parentes próximos com paradeiro desconhecido há mais de 5 anos. Exames paternos e fraterno, até o momento; são normais. Aguardamos resultados dos genomas. Ao exame clínico apresentou fácies normal, bom estado geral, PASMMSS $=120 / 80 \mathrm{mmHg}$, PASMMII 180/110mmHg, $\mathrm{FC}=56 \mathrm{bpm}, \mathrm{T}=36,7$ ? $\mathrm{C}, \mathrm{FR}=16 \mathrm{ipm}$.

\section{CONTROLE DE EXAMES LABORATORIAIS VERIFI- CADO EM QUATRO CATEGORIAS DE JOGADORES DE FUTEBOL EM PRÉ-TEMPORADA}

Autor: Alberto Azevedo Alves Teixeira

Co-autores: Teixeira A.A.A., Pedrinelli A., Angeli F.J., Facci E.S., Galotti R., Favano A., Gondo M.M.., Silva P.R.S., Greve J.M.D'A., Amatuzzi M.M.

Apresentador: Alberto Azevedo Alves Teixeira

Serviço: Laboratório de Estudos do Movimento do Instituto de Ortopedia e Traumatologia (IOT) do HCFMUSP

Introdução: A prática competitiva no esporte de alto rendimento requisita dos atletas condições de saúde compatíveis para responder as frequentes e intensas solicitações funcionais. Objetivo: Verificar antes de iniciar o período competitivo a normalidade ou alteração de marcadores laboratoriais por meio de parâmetros bioquímicos. Material e métodos: Foram submetidos a exames laboratoriais 98 jogadores de futebol de quatro categorias de um clube da $1{ }^{a}$ divisão da cidade de São Paulo: infantil (26), juvenil (25), juniores (15) e profissional (32).

Resultados:

\begin{tabular}{|l|c|c|c|c|c|}
\hline ALTERAÇÕES & $\begin{array}{c}\text { INFANTIL } \\
\mathrm{N}=26 \\
(\%)\end{array}$ & $\begin{array}{c}\text { JUVENIL } \\
\mathrm{N}=25 \\
(\%)\end{array}$ & $\begin{array}{c}\text { JUNIORES } \\
\mathrm{N}=15 \\
(\%)\end{array}$ & $\begin{array}{c}\text { PROFISSIONAL } \\
\mathrm{N}=32 \\
(\%)\end{array}$ & $\begin{array}{c}\text { TODAS AS } \\
\text { CATEGORIAS } \\
\text { N=98 } \\
(\%)\end{array}$ \\
\hline HIPOGLICEMIA & 42 & 76 & 80 & 62 & 63 \\
\hline VERMINOSE & 30 & - & 67 & 19 & 43 \\
\hline URINA & 35 & 24 & 47 & 16 & 27 \\
\hline ANEMIA & 4 & 8 & 7 & 9 & 7 \\
\hline ÁCIDO ÚRICO & - & 4 & - & 6 & 3 \\
\hline HIPOPOTASSEMIA & - & - & - & 3 & 1 \\
\hline
\end{tabular}

Conclusão: Os resultados demonstraram que a verificação de exames laboratoriais em jogadores de futebol, independentemente da categoria, deve ser uma prática rotineira, pois além do aspecto preventivo sobre a integridade física do atleta, essas alterações poderão interferir no desempenho atlético durante treinamentos e competições. 


\section{PERFIL ISOCINÉTICO DOS MÚSCULOS FLEXORES E EXTENSORES E DE JOELHOS EM JOGADORES DE FUTEBOL NA FASE PRÉ-TEMPORADA}

Autor: Júlia Maria D’Andrea Greve

Co-autores: Greve J.M.D’A., Silva P.R.S., Pedrinelli A., Gon-

do M.M., Favano A., Teixeira A.A.A., Facci E.S., Galotti R., Angelini F.J., Amatuzzi M.M.

Apresentador: Marcelo Masso Gondo

Serviço: Laboratório de Estudos do Movimento do Instituto de Ortopedia e Traumatologia (IOT) do HCFMUSP

Introdução: A dinamometria isocinética computadorizada é uma técnica de avaliação funcional muscular com crescente utilização no esporte. A valorização tem sido reconhecida pela objetividade e eficiência do método em verificar desequilíbrio músculo-articular, em orientar condutas preventivas e na reabilitação de grupos musculares lesionados. Objetivo: Verificar o desempenho isocinético dos músculos flexores e extensores das articulações de joelhos nas pernas dominante e não dominante em jogadores de futebol antes de iniciar a temporada futebolística. Material e métodos: Foram avaliados 22 futebolistas com idades entre 18 e 33 anos. Todos foram submetidos a teste isocinético em velocidades angulares de $60^{\circ} \cdot \mathrm{S}^{-1} \mathrm{e}$ $300^{\circ} \cdot \mathrm{S}^{-1}$ no dinamômetro (modelo 6000, Cybex, EUA). Resultados: Pico de torque dos flexores das pernas dominante e não dominante a $60^{\circ} \cdot \mathrm{S}^{-1}: 155 \pm 17 \mathrm{Nm}$ e $150 \pm 19 \mathrm{Nm}$ e dos extensores foi $255,5 \pm$ $37,5 \mathrm{Nm}$ e $278,5 \pm 54,0 \mathrm{Nm}$. A relação percentual flexão/extensão em ambas as pernas foi de $59 \pm 9,5 \%$ e $55 \pm 9 \%$, respectivamente. $\mathrm{O}$ pico de torque dos flexores a $300^{\circ} \cdot \mathrm{S}^{-1}$ foi de $105 \pm 17 \mathrm{Nm}$ e $106 \pm$ $13 \mathrm{Nm}$ e os extensores foi de $144 \pm 26 \mathrm{Nm}$ e $152 \pm 34 \mathrm{Nm}$. A relação percentual flexão/extensão em ambas as pernas foi de $75 \pm 17 \%$ e 73 $\pm 16 \%$, respectivamente. Apesar dos valores médios quando comparados não apresentarem diferença estatística (ANOVA) significante, quando agrupamos todos os jogadores com desequilíbrio a $60^{\circ} \mathrm{S}^{-1} \mathrm{e}$ a $300^{\circ} \cdot \mathrm{S}^{-1}$ foi verificado que $50 \%$ e $68 \%$ respectivamente apresentavam quociente abaixo do valor de referência para normalidade, ao contrário, os músculos extensores em ambas as pernas apresentaram somente 9\%. Conclusão: A grande maioria dos futebolistas mostrou enfraquecimento sobretudo dos músculos flexores necessitando exercícios específicos de fortalecimento. As velocidades angulares lenta e rápida foram marcadores eficientes para a avaliação objetiva e segura dos músculos flexores e extensores da articulação de joelhos em jogadores de futebol.

\section{INFLUÊNCIA DA ATIVIDADE FÍSICA NA FLEXIBI- LIDADE E AGILIDADE DE IDOSOS ATIVOS E ASI- LADOS}

Autor: Adriana B. Truccolo

Co-autores: Gonçalves A.K., Barahona R.A., Argenta R.

Apresentador: Adriana Truccolo

\section{Serviço: Universidade Luterana do Brasil}

Introdução: Tem sido observada diminuição tanto na flexibilidade (de $20 \%$ a $30 \%$ quando atingem a idade de 70 anos) quanto na agilidade de idosos, comprometendo, com isso, a independência funcional dos mesmos. A redução em tais variáveis tem sido atribuída a doenças crônicas como a osteoartrite e ao sedentarismo. Material/ casuística e métodos, ou caso clínico: Objetivo: O objetivo desta investigação foi comparar a flexibilidade e agilidade de idosos asilados com idosos ativos a fim de observar a influência exercida por um programa de atividade física nessas capacidades motoras. Local de coleta: Os dados foram coletados em um asilo e em centro de convivência na cidade de Canoas, estado do Rio Grande do Sul. Amostra: A amostra foi composta por 42 indivíduos na faixa etária de 61 a 83 anos de idade, sendo 21 residentes em um asilo e 21 pertencentes a um grupo de convivência onde reúnem-se duas vezes por semana. Dos 21 idosos asilados, 9 eram do sexo feminino e 12 do sexo masculino; e dos 21 idosos ativos, 17 eram do sexo feminino e 4 do sexo masculino. Instrumento utilizado: Os instrumentos utilizados para acessar flexibilidade e agilidade foram os propostos por Rikli e Jones no livro Senior Fitness Test Manual, Human Kinetics, 2001. Resultados/conclusão: Os dados demonstraram que 100\% dos idosos asilados apresentaram resultados para o teste de agilidade inferiores para sexo e faixa etária; enquanto que $95 \%$ dos idosos ativos apresentaram resultados para o teste de agilidade superiores ao normal para sexo e faixa etária. Foram observadas diferenças significativas na agilidade entre os dois grupos, a um nível de significância de 5\%. Com relação à flexibilidade foram observadas similaridades nos resultados dos dois grupos. Somente $24 \%$ e $38 \%$ dos idosos, ativos e asilados, respectivamente apresentaram flexibilidade acima do normal para sexo e faixa etária. O restante da amostra apresentou resultado para flexibilidade inferior ao normal para sexo e idade. Não foram observadas diferenças significativas entre os grupos a um nível de significância de 5\%. Discussão e conclusão: Podese observar influência de um programa regular de atividade física com relação à agilidade dos idosos, porém o mesmo não pode ser afirmado com relação à flexibilidade. Acreditamos que exercícios mais específicos devam ser introduzidos ao programa a fim de aprimorar a flexibilidade desses idosos.

\section{NÍVEL DE CONSCIÊNCIA EM RELAÇÃO A PREVEN- Ç̃̃O DE CÂNCER DE PELE EM PRATICANTES DE ATIVIDADE FÍSICA “OUT DOOR”}

\author{
Autor: Marcelo Baboghluian
}

Co-autor: Contreras M.L.

Apresentador: Marcelo Baboghluian

Serviço: Projeto Marazul - Centro de Medicina Esportiva

A incidência de câncer de pele tem sido discutida em diversos níveis, a relação entre exposição solar e o aparecimento deste tipo de alteração estrutural já está bem relacionada. A proposta deste trabalho foi verificar o nível de consciência de praticantes de esportes ao ar livre, também chamados de "out door “, em relação a prevenção do câncer de pele, evidenciando-se a importância da orientação clínica em indivíduos deste grupo, além de uma avaliação clínica periódica específica para esta doença. Para tanto foram entrevistadas 724 pessoas praticantes de atividades físicas na praia do litoral paulista, entre 10 de janeiro de 2002 e 10 de fevereiro de 2002, os entrevistados foram escolhidos por estarem realizando algum tipo de atividade esportiva no ambiente praia, não levando-se em consideração idade ou sexo. Os resultados são mostrados abaixo:

Não me protejo do sol: 13,26\% (96 entrevistados)

Não uso protetor, mas uso boné e camiseta: 2,35\% (17 entrevistados) 
Só passo protetor uma vez, quando chego à praia: 41,16\% (298 entrevistados)

Passo protetor mais de duas vezes durante a prática: 37,98\% (275 entrevistados)

Uso protetor diariamente, mesmo não indo à praia:5,25\% (38 entrevistados)

Ao analisarmos a pesquisa observamos que $13,26 \%$ dos entrevistados simplesmente não usa nenhum tipo de fotoproteção, e que $41,16 \%$ o faz somente uma vez durante o período que fica exposta aos raios solares; concluímos que é válida a inclusão de avaliação dermatológica no exame clínico periódico desta população e que campanhas mais esclarecedoras devem ser dirigidas ao grupo de praticantes de atividades físicas ao ar livre.

\section{INFLUÊNCIA DAS ALTERAÇÕES ANTROPOMÉTRI- CAS SOBRE O DESEMPENHO MOTOR DE HOMENS E MULHERES}

Autor: Fábio L. Orsatti

Co-autores: Silva C.C., Daiuto H.P., Cardoso M.A., Simonetti L.A., Maestá N., Pereira A.F., Moreli M.Y.G., Burini R.C.

Apresentador: Fábio L. Orsatti

Serviço: UNESP - Botucatu

Introdução: A capacidade de realizar tarefas motoras é influenciada por diversos fatores dentre os quais os antropométricos. Material/casuística e métodos, ou caso clínico: Com o objetivo de investigar a influência de alterações antropométricas sobre as variações de desempenho motor, usualmente associados ao envelhecimento, foram estudados 64 homens $(54=$ ? 9,3 anos) e 120 mulheres $(54,9$ ? 9,3 anos), voluntários participantes de projeto de extensão universitária envolvendo condicionamento aeróbio e aconselhamento alimentar. A amostra era constituída, em média, de pré-obesos/obesos com $\mathrm{IMC}=28,4 ? 3,3 \mathrm{~kg} / \mathrm{m} 2$ para homens $(\mathrm{M})$ e $28,4 ? 4,5 \mathrm{~kg} / \mathrm{m} 2$ para mulheres $(\mathrm{F})$, associadamente à hiperadiposidade corpórea (bioimpedância) de 27,8 ? 4,7\% e 34,1 ? 7,8\% respectivamente para M e F e adiposidade abdominal ( $\mathrm{RCQ}=$ relação cintura/quadril) de 0,98 ? $0,1(\mathrm{M})$ e 0,87 ? 0,1 (F). Os testes físicos foram efetuados em um único dia na seqüência: flexibilidade (FLEX = sentar e alcançar), equilíbrio (30 segundos em pé com uma única perna), força de membros superiores dos lados direito e esquerdo (FMSD e FMSE) (dinamômetro), inferiores (FMI = sentar e levantar da cadeira) e VO2 máximo (teste de milha). Para análise estatística utilizou-se o coeficiente de correlação linear de Pearson. Resultados/conclusão: Em ambos os sexos foram observadas correlações positivas $(\mathrm{p}<0,05)$ do peso e da estatura com a FMS e negativas $(\mathrm{p}<0,05)$ do IMC e da $\%$ de gordura com o equilíbrio e VO2Max. A RCQ correlacionou-se negativamente com o VO2Max. Nas mulheres, o excesso de peso e das adiposidades corpórea e abdominal influenciaram negativamente o equilíbrio (IMC $\mathrm{r}=-0,19, \mathrm{RCQ} \mathrm{r}=-0,20, \%$ GORD $\mathrm{r}=-0,19$ ), flexibilidade (peso $r=-0,28, \mathrm{IMC} r=-0,27, \mathrm{RCQ} r=-0,25, \%$ GORD $\mathrm{r}=-0,29)$, FMI (RCQ $r=-0,20)$ e VO2Max. (peso $r=-0,40$, IMC $r=$ $-0,53, \%$ GORD $r=-0,53$, RCQ $r=-0,48)$. Assim, exceto FMS que sofreu influencia positiva do peso todos os demais índices motores sofreram influencia negativa dos excessos de peso e de adiposidade, particularmente as mulheres. CNPq-AI

\section{HÉRNIA MUSCULAR CAUSANDO FASCICULAÇÕES EM UM ATLETA: RELATO DE CASO}

Autor: André Pedrinelli

Co-autores: Saito M., Amatuzzi M.M., Camargo A.J.S.

Apresentador: André Pedrinelli

Serviço: IOT - HC-FMUSP

Introdução: A hérnia muscular na perna é a protrusão de uma parte da sua musculatura através de um defeito focal da fáscia que a recobre. Tal lesão é mais comum no músculo tibial anterior, mas também pode envolver os músculos extensor longo dos dedos, fibular longo, fibular curto e gastrocnêmio. Sua localização mais comum é no terço médio e distal da perna, no compartimento anterior. Ocorre em atletas, militares e profissionais que exigem muita força nas suas pernas com movimentos repetitivos. As hérnias musculares costumam ser tratadas de maneira conservadora. Quando ocorre falha no tratamento clínico, indica-se o tratamento cirúrgico. Material/casuística e métodos, ou caso clínico: Neste relato, apresentamos um atleta corredor, com queixa de dores nas pernas ao término das sessões de treinamento e fasciculações nas pernas à noite. Ao exame físico, notou-se abaulamento bilateral nas pernas. A investigação descartou lesões tumorais através de uma biópsia. Os exames bioquímicos não mostraram nenhum sinal de miólise ou distúrbio hidro-eletrolítico. Os exames de ultra-som e ressonância magnética mostraram hérnias musculares bilaterais Nas pernas. A eletromiografia dinâmica demonstrou distúrbios na condução somente no ventre muscular herniado. Devido à falha do tratamento conservador e ao quadro clínico concomitante de síndrome compartimental crônica, o paciente foi submetido a fasciotomia bilateral das pernas.

\section{VARIAÇÃO DE PARÂMETROS DE IMPEDÂNCIA COM O NÍVEL DE ATIVIDADE FÍSICA EM JOVENS} Autor: Adilson A Dias

Co-autores: Monreal M.A., Formiga F.B., Gajardo J.R.C., Varga J., Monte O.

Apresentador: Maíra Monreal

Serviço: Faculdade de Ciências Médicas da Santa Casa de São Paulo

Introdução: Há um interesse crescente no estudo das variações dos parâmetros de impedância humana e sua variação fisiológica. Uma área de grande interesse é o estudo da fisiologia do esporte. O objetivo deste estudo é a variação dos parâmetros de impedância em jovens saudáveis e sua correlação com o nível de atividade física. Material/casuística e métodos, ou caso clínico: Foram estudados 287 jovens (196 sexo masculino-m- e 91 sexo feminino-f) de 17 a 25 anos, distribuídos por nível de atividade física: Nível I: Sedentários: 64 jovens ( 30 m e 34 f), Nível II: atletas ocasionais ( 1 a 2 vezes por semana): 118 jovens (76 m, 42 f), Nível III: atividade física maior que 3 vezes por semana ou mais: 48 jovens ( $33 \mathrm{~m}, 15 \mathrm{f}$ ) e Nível IV: cadetes da Academia da Força Aérea, com treinamento físico diário: 60 cadetes do sexo masculino. Método: $\mathrm{O}$ estudo consistiu na determinação do peso e altura dos jovens e medida de resistência e reatância capacitiva de corpo total, e calculo do ângulo de fase. Resultados/conclusão: Apresentados em média (desvio padrão). Peso: Nível I: m: 69,5 (9,4) kg, f: 57,5 (10,9) kg, Nível II: m: 74,5 (1,1) kg, f: 58,5 (9,0) kg, Nível III: m: 73,0 (8,8), f: 58,3: $(8,8) \mathrm{kg}$. Nível IV: 67,0 (8,1) kg. Resistência (em Ohms): Nível I: m: 520,9 (68,7), f: 
640,3 (65,5), Nível II: m: 492,5 (77,1), f: 595,3 (71,4), Nível III: m: 465,8 (48,6), f: 586,3 $(83,9)$ e Nível IV: 447,5 $(49,5)$ Reatância Capacitiva (em Ohms): Nível I: m: 61,2 (8,1), f: 65,2 (7,4), Nível II: m: 60,5 (6,7), f: 65,7 (8,3), Nível III: m: 62,1 (7,5), f: 64,9 (6,0), Nível IV: $61,5(10,1)$ Ângulo de fase (em Graus): Nível I: m: $6,73(0,72), \mathrm{f}$ : 5,83 (0,54), Nível II: m: 7,07 (072), f: 6,33 (0,70), Nível III: m: 7,60 $(0,76)$, f: 6,43 (0,96), Nível IV: 7,82 (0,92). Conclusões: 1) A resistência foi maior nas mulheres em todos os grupos, provavelmente por maior quantidade de gordura. 2) A resistência diminuiu com aumento do nível de atividade física, provavelmente por diminuição da quantidade de gordura corporal. 3) Não houve diferença estatisticamente significativa na reatância capacitiva comparando os grupos e os sexos. 4) $\mathrm{O}$ ângulo de fase foi maior nos homens que nas mulheres. 5) $\mathrm{O}$ ângulo de fase aumentou progressivamente com o aumento do nível de atividade física 6) $\mathrm{O}$ método de impedância pode ser utilizado para acompanhar a evolução de atletas em programas de treinamento físico.

\section{APLICAÇÃO DE PROGRAMAS DE QUALIDADE DE VIDA E DE SAÚDE SOCIAL, JUNTO A ALUNOS DA REDE DE ENSINO PÚBLICO DE RIBEIRÃO PRETO "ESCOLATIVIDADE"}

Autor: Antonio Mauro de Souza Sebastião

\section{Apresentador: Antonio Mauro de Souza Sebastião}

Os problemas que afetam a saúde em nossa cidade (material, econômico, pessoal, educacional, cultural ou científico) e, nesse sentido, nossa proposta visa possibilitar, mediante métodos científicos e aplicáveis a realidade social, a todos, através do equilíbrio de sua saúde física e mental, obter ganhos de produtividade, longevidade e de qualidade, em todos os aspectos e atividades da vida. Grupos de interesses crianças, adolescentes, jovens e portadores de deficiência. A aplicação do Programa executado junto a estabelecimentos de ensino. As Situações-Problemas: as Situações-Problemas identificadas no ambiente escolar afetam todos os que nele interagem e, via de conseqüência, o próprio ambiente em si, causando prejuízos de ordem social, material, econômica, psíquica, física, aos alunos, professores, direção, funcionários, quanto à comunidade na qual se insere Métodos. A implantação do PROGRAMA RIBEIRÃO CRIANÇA ESCOLATIVIDADE visa identificar as Situações-Problemas, para as quais propõe soluções fundadas em técnicas diversas, assim como atividades, físicas, terapêuticas, ergonômicas, nutricionais, psicológicas, culturais entre outros, cujo objetivo é a solução dos problemas identificados e a prevenção de sua ocorrência. Resultados do Programa: redução de faltas, afastamentos médicos, licenças, diminuição, controle e prevenção da evasão escolar, da violência e do envolvimento de menores com a criminalidade; melhoria das condições pessoais e grupais dos envolvidos psiquicamente; emocionalmente, intelectualmente e fisicamente, com reflexos positivos nos diversos níveis de relacionamento; aluno-aluno, aluno-professor, aluno-professor-direção, aluno-professor-direçãofuncionário, aluno-professor-direção-funcionário-família. Conclusão: O Programa possibilita ao aluno melhoria das condições gerais de saúde, mudanças de hábitos, a adoção e incorporação definitiva, em sua vida, de hábitos saudáveis, que lhe trarão benefícios imediatos e para o futuro, oferecendo-lhe os meios que poderão fazer dele pessoa saudável, produtiva e útil a sociedade. As atividades extracurriculares, se desenvolverão entre práticas e teóricas orientativas. Unitermos: 1. Saúde e Qualidade de Vida; 2. Alunos da Rede Municipal de Ensino; 3. Atividades Físicas, Ergonômicas dentre outras.

\section{SUTURA DO MENISCO COM IMPLANTES ABSOR- VÍVEIS}

Autor: Arnaldo José Hernandez

Co-autores: Laraya M.H., Koyama C., Martinelli Fo M.

Apresentador: Marcos Henrique Laraya

Serviço: Sírio Libanês, Beneficência Portuguesa e Hospital Jaraguá

Introdução: Apesar de em 1936 King ter demonstrado que a meniscectomia em cães causava alterações degenerativas no joelho, durante muitos anos a meniscectomia foi defendida por diversos autores como Smillie, Dandy e Jackson. A sutura meniscal foi sugerida no século IXX por Thomas Annandale, e foi revivida apenas na década de 80, com base nos estudos de Arnoczky e col. a respeito do suprimento sanguíneo dos meniscos e da sua possibilidade de cicatrização na zona periférica. Hoje é consenso que os meniscos devam ser preservados sempre que possível, devido as alterações degenerativas acarretadas pela meniscectomia. Objetivo: Avaliar os resultados clínicos da sutura meniscal feita com implantes absorvíveis. Material e métodos: São avaliados clinicamente 19 pacientes (19 joelhos - 15 meniscos mediais e 5 laterais) submetidos à sutura meniscal com a utilização de 2 tipos de implantes absorvíveis (ácido polilático), "arrow ${ }^{\circledR ”}$ e “clear-fix ${ }^{\circledR ”}$. O estudo consta 15 pacientes do sexo masculino e 4 feminino. A idade média foi de 26,8 anos com mínima de 16 e máxima de 44 . O tempo de seguimento variou entre 9 e 26 meses com média de 18 . A técnica operatória constituiu-se da sutura de um ou ambos os meniscos (1 caso) via artroscópica com "arrow" em 15 pacientes e "clear fix" em 4. Dos 19 indivíduos, 6 foram submetidos à sutura meniscal isolada, 11 associada à reconstrução do LCA e 2 à reconstrução do LCA com osteotomia valgizante da tíbia no mesmo ato cirúrgico. Os resultados foram avaliados clinicamente de acordo com o exame físico incluindo-se os testes ligamentares e as manobras de Appley e Mc Murray. A avaliação funcional pré e pós-operatória do joelho foi realizada pela escala de Lysholm modificada. Resultados e conclusões: Todos os pacientes tiveram suas manobras meniscais negativadas no pós-operatório. A pontuação média pré-operatória (Lysholm) foi de 39,8, subindo no pós-operatório para 91,5. Em duas ocasiões, após período assintomático, houve necessidade de nova artroscopia para realização de meniscectomia parcial por bloqueio articular, sendo essas em casos de sutura em lesão isolada sem mecanismo rotacional (flexão forçada). Apesar da dificuldade de avaliação dos resultados, já que a maioria das suturas são realizadas em associação com outros procedimentos, os autores concluem que a sutura com implantes absorvíveis tem se mostrado eficientes até o momento e tecnicamente mais simples que a sutura convencional. 